\title{
Haplotypes of the porcine peroxisome proliferator-activated receptor delta gene are associated with backfat thickness Karina Meidtner ${ }^{1}$, Hermann Schwarzenbacher ${ }^{1}$, Maren Scharfe ${ }^{2}$, Simone Severitt ${ }^{2}$, Helmut Blöcker ${ }^{2}$ and Ruedi Fries*1
}

\author{
Address: ${ }^{1}$ Chair of Animal Breeding, Technical University of Munich, Hochfeldweg 1, 85354 Freising - Weihenstephan, Germany and ${ }^{2}$ Department \\ of Genome Analysis, Helmholtz Centre for Infection Research, Inhoffenstraße 7, 38124 Braunschweig, Germany \\ Email: Karina Meidtner - karina.meidtner@tierzucht.tum.de; Hermann Schwarzenbacher - hermann.schwarzenbacher@tierzucht.tum.de; \\ Maren Scharfe - maren.scharfe@helmholtz-hzi.de; Simone Severitt - simone.severitt@gmx.de; Helmut Blöcker - bloecker@helmholtz-hzi.de; \\ Ruedi Fries* - ruedi.fries@tierzucht.tum.de \\ * Corresponding author
}

Published: 30 November 2009

BMC Genetics 2009, 10:76 doi:10.1186/1471-2156-10-76
Received: 18 January 2009

Accepted: 30 November 2009

This article is available from: http://www.biomedcentral.com/I47I-2I56/I0/76

(c) 2009 Meidtner et al; licensee BioMed Central Ltd.

This is an Open Access article distributed under the terms of the Creative Commons Attribution License (http://creativecommons.org/licenses/by/2.0), which permits unrestricted use, distribution, and reproduction in any medium, provided the original work is properly cited.

\begin{abstract}
Background: Peroxisome proliferator-activated receptor delta belongs to the nuclear receptor superfamily of ligand-inducible transcription factors. It is a key regulator of lipid metabolism. The peroxisome proliferator-activated receptor delta gene (PPARD) has been assigned to a region on porcine chromosome 7 , which harbours a quantitative trait locus for backfat. Thus, PPARD is considered a functional and positional candidate gene for backfat thickness. The purpose of this study was to test this candidate gene hypothesis in a cross of breeds that were highly divergent in lipid deposition characteristics.

Results: Screening for genetic variation in porcine PPARD revealed only silent mutations. Nevertheless, significant associations between PPARD haplotypes and backfat thickness were observed in the F2 generation of the Mangalitsa $\times$ Piétrain cross as well as a commercial German Landrace population. Haplotype 5 is associated with increased backfat in F2 Mangalitsa $\times$ Piétrain pigs, whereas haplotype 4 is associated with lower backfat thickness in the German Landrace population. Haplotype 4 and 5 carry the same alleles at all but one SNP. Interestingly, the opposite effects of PPARD haplotypes 4 and 5 on backfat thickness are reflected by opposite effects of these two haplotypes on PPAR- $\delta$ mRNA levels. Haplotype 4 significantly increases PPAR- $\delta$ mRNA levels, whereas haplotype 5 decreases mRNA levels of PPAR- $\delta$.

Conclusion: This study provides evidence for an association between PPARD and backfat thickness. The association is substantiated by mRNA quantification. Further studies are required to clarify, whether the observed associations are caused by PPARD or are the result of linkage disequilibrium with a causal variant in a neighbouring gene.
\end{abstract}

\section{Background}

In various pig populations genome wide studies have been carried out to map quantitative trait loci (QTL) and to develop genetic markers for breeding. This resulted in more than 400 QTL for fatness [1]. The numerous QTL studies revealed chromosomal regions repeatedly linked to fatness traits. Some of the most significant QTL for backfat were identified on porcine chromosome 7 [2-5]. 
Most studies report a paradox of lower backfat to be caused by the allele originating from the breed, usually Meishan, with the higher backfat mean [2,5-7]. In this QTL region the peroxisome proliferative activated receptor delta (PPAR- $\delta$ ) gene was mapped $[8,9]$. PPAR- $\delta$ is involved in the regulation of lipid metabolism, energy balance and insulin sensitivity [10]. Therefore, PPARD is considered to be a functional as well as positional candidate gene for backfat thickness. A study of 74 porcine SNPs across 5 chromosomes, with the majority located in proximity to backfat QTL, revealed an association of two markers in PPARD with backfat thickness [11].

The metabolic and histochemical characterisation of fat and muscle tissue from pigs with the chromosome 7 QTL alleles from Meishan and Large White showed differences in adipocyte size and number in backfat as well as differences in the basal rate of glucose incorporation into lipids and activity of lipogenic enzymes [12]. Therefore, PPARD is considered to be a promising candidate gene for the observed QTL effect [12]. A microarray-based experiment aiming at the identification of differentially expressed genes between lean Piétrain and 'obese' German Landrace pigs revealed an up-regulation of PPARD in Piétrain [13]. This suggests a possible effect on lipid deposition and strengthens the hypothesis of PPARD being a candidate gene for fatness.

The objective of this study was to systematically screen the PPAR- $\delta$ gene for polymorphisms and carry out association studies with identified variants. Furthermore, mRNA expression of PPARD variants was analysed in liver.

\section{Results}

Gene structure, splice variants and their expression

The genomic structure of the porcine PPARD was previously unknown. Therefore, it had to be determined from the porcine RefSeq mRNA sequence that consists of eight exons [GenBank: NM 214152]. Genomic sequence data was obtained by sequencing a porcine BAC (PigE255B24). The assembly of the BAC shot gun sequences resulted in two genomic contigs containing PPARD. Sequence data was submitted to gene bank [GenBank: EU169095]. The first contig comprises the putative promoter, exon 1, the complete intron 1, exon 2 and approximately $15.7 \mathrm{~kb}$ of intron 2 (Figure 1). The second contig covers the region from exon 3 to exon 8 and $12.2 \mathrm{~kb}$ of the region 3 ' of the last exon (Figure 1). The resulting PPARD mRNA sequence is complete. All introns follow the GTAG rule. The protein-coding sequence starts in exon 3 and ends in exon 8. The derived amino acid sequence is $94.6 \%$ identical to the sequence of human PPAR- $\delta$. The common PPAR- $\delta$ transcript includes all eight exons. In addition, a splice variant without exon 2 was detected. Both PPAR- $\delta$ splice variants seem to be ubiquitously expressed since they were detected in liver, lung, backfat, muscle, kidney, brain, spleen and heart tissue.

\section{Polymorphisms and haplotypes}

All eight exons of porcine PPARD, exon flanking intronic regions and $2000 \mathrm{bp}$ of the putative promoter region were screened for genetic variation by resequencing the parental generation of a Mangalitsa $\times$ Piétrain intercross and three unrelated animals of each of the German Landrace, German Large White and Duroc breeds. A total of 25 variants were identified, comprising 22 SNPs, two insertion/ deletion polymorphisms and one stretch of a variable number of cytosins (Table 1). Two out of 22 SNPs are located in the protein-coding region, but they do not change the amino acid sequence. The number of cytosins in the polyC stretch varied between 11 and $14 \mathrm{Cs}$ in the analysed animals. However, it was impossible to determine the exact number of $\mathrm{Cs}$ of the polyC stretch in some heterozygous animals. For that reason, only 24 polymorphisms were used to infer haplotypes.

A total of five haplotypes were detected with haplotypes 4 and 5 being identical at 23 out of 24 polymorphisms (Table 2). Both founding Mangalitsa boars of the resource population were homozygous for haplotype 1 . The haplotype frequencies were $17 \%, 46 \%, 17 \%, 8 \%$ and $12 \%$ for haplotype 1, 2, 3, 4 and 5, respectively, in the twelve

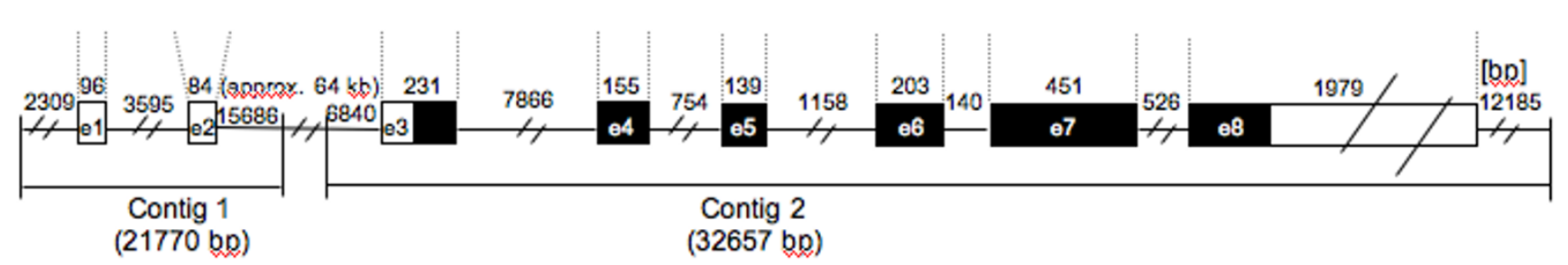

Figure I

Exon-Intron structure of PPARD. 
Table I: Polymorphisms in PPARD

\begin{tabular}{|c|c|c|c|}
\hline dbSNP number & Variant & Localisation & Predicted function \\
\hline ss 161109991 & SNP & Promoter & unknown \\
\hline ss 161109992 & SNP & Promoter & unknown \\
\hline ss I6I I09993 & SNP & Promoter & unknown \\
\hline ss 161109994 & SNP & Promoter & unknown \\
\hline ss I6II 09995 & SNP & Promoter & affects putative ETS-domain TFBS \\
\hline ss 161109996 & SNP & Intron I & unknown \\
\hline ss I6I I09997 & SNP & Exon 2 (5' UTR) & Minor effect on mRNA structure \\
\hline ss 161109998 & SNP & Exon 2 (5' UTR) & Minor effect on mRNA structure \\
\hline ss 161109999 & SNP & Intron 3 & unknown \\
\hline ss 161110000 & SNP & Intron 4 & unknown \\
\hline ss 161110001 & SNP & Intron 4 & unknown \\
\hline ss 161110002 & SNP & Intron 5 & unknown \\
\hline ss 161110003 & InDel & Intron 5 & unknown \\
\hline ss 161110004 & SNP & Intron 5 & unknown \\
\hline ss 161110005 & SNP & Intron 5 & unknown \\
\hline ss 161110006 & SNP & Intron 5 & unknown \\
\hline ss 161110007 & SNP & Intron 6 & unknown \\
\hline ss I6III 0008 & InDel & Intron 6 & unknown \\
\hline ss 161110009 & SNP & Exon 7 (coding) & synonymous, minor effect on mRNA structure \\
\hline ss 161110010 & SNP & Exon 8 (coding) & synonymous, minor effect on mRNA structure \\
\hline ss 161151656 & SNP & Exon 8 (3' UTR) & minor effect on mRNA structure \\
\hline ss 161151657 & SNP & Exon 8 (3' UTR) & no effect on mRNA structure \\
\hline ss 161151658 & SNP & Exon 8 (3' UTR) & no effect on mRNA structure \\
\hline ss 161151659 & SNP & Exon 8 (3' UTR) & minor effect on mRNA structure \\
\hline ss 161151660 & polyC & Exon 8 (3' UTR) & minor effect on mRNA structure \\
\hline
\end{tabular}

Piétrain parental animals. Four SNPs (polymorphisms ss161109995, ss161109998, ss161110009 and ss161110010) are sufficient to tag the five haplotypes.

\section{Association studies}

Association between PPARD haplotypes and backfat thickness was initially studied in the F2 generation of a Mangalitsa $\times$ Piétrain cross. Analysis of haplotype frequencies in the F1 generation revealed that haplotype 4 was not passed on to the F1 generation and was consequently assumed to be absent in the F2 generation. Therefore, SNPs ss161109995, ss161109998 and ss161110010 were sufficient to distinguish the remaining four haplotypes and were used to genotype 599 F2 animals by diagnostic restriction enzyme assays. Association analyses of PPARD variants and backfat were carried out and revealed a significant association between PPARD haplotype 5 and backfat thickness $(\mathrm{p}=0.022$, Table 3$)$ in the Mangalitsa $\times$ Piétrain cross when contrasted against all other haplotypes. However, the p-value is above the $5 \%$ bonferoni corrected significance threshold of 0.0125 that corrects for testing of four different haplotypes. Heterozygous animals carrying one haplotype 5 allele showed an increase in backfat thickness of $2.43 \mathrm{~mm}$ (Table 3).

This result was followed up in unrelated animals of a commercial pig breed. The selection of a suitable study population was problematical because haplotype 5 is infrequent in all analysed pig populations (Figure 2). The highest frequency was observed in Piétrain and is estimated at 5\% (Figure 2). Nevertheless, haplotype 4 is identical to haplotype 5 at all but one SNP (ss161110009, Table 2) and haplotype 4 is frequent in German Landrace, German Large White and Duroc (Figure 2). German Landrace was chosen because it was expected to exhibit both a relatively high frequency of haplotype 4 and possibly a few animals carrying haplotype 5 . A total of 681 animals were successfully genotyped. The frequencies were $10 \%$, $44 \%, 7 \%, 37 \%$ and 2\% for haplotypes 1, 2, 3, 4 and 5, respectively. Genotype frequency of all tag SNPs did not deviate from Hardy-Weinberg equilibrium. Backfat thickness was significantly decreased by PPARD haplotype 4 ( $\mathrm{p}$ $=0.034$ ) when tested against all other haplotypes. In contrast, haplotype 5 that differs only in one SNP from haplotype 4 increased backfat thickness in the Mangalitsa $\times$ Piétrain population (Table 3). Haplotype 5 has no significant effect on backfat thickness $(\mathrm{p}=0.242)$ in the German Landrace population. The power to detect a significant association $(\mathrm{p}<0.05)$ of the rare haplotype 5 $(\mathrm{MAF}=2 \%)$ within the analysed German Landrace population of 700 individuals is only 0.05 . Therefore, we cannot exclude an effect of haplotype 5 on backfat thickness in this population. The least square means of backfat thickness within the group of pigs carrying one haplotype 5 allele is higher than in pigs carrying no haplotype 5 (Table 3), which is the same trend as seen in the Mangal- 
Table 2: Haplotypes of PPARD

\begin{tabular}{|c|c|c|c|c|c|}
\hline \multirow[t]{2}{*}{ SNP } & \multicolumn{5}{|c|}{ PPARD Haplotype } \\
\hline & I & 2 & 3 & 4 & 5 \\
\hline ss | 6 I I 0999 | & $A$ & $A$ & A & G & G \\
\hline ss I 6 I I 09992 & G & G & $A$ & G & G \\
\hline ss I 61109993 & $A$ & A & G & $\mathrm{G}$ & G \\
\hline ss I 61109994 & C & C & C & $\mathrm{T}$ & $\mathrm{T}$ \\
\hline ss I 61109995 & $A$ & $A$ & A & C & C \\
\hline ss I 61109996 & $A$ & $A$ & G & G & G \\
\hline ss I 61109997 & C & C & C & $\mathrm{T}$ & $\mathrm{T}$ \\
\hline ss I 61109998 & $\mathrm{G}$ & G & $A$ & $A$ & $A$ \\
\hline ss I 61109999 & G & G & A & G & G \\
\hline ss I 61110000 & $\mathrm{~T}$ & $\mathrm{~T}$ & $\mathrm{~T}$ & C & C \\
\hline ss 161110001 & G & G & G & $A$ & $A$ \\
\hline ss I 61110002 & $\mathrm{C}$ & C & $\mathrm{T}$ & $\mathrm{C}$ & C \\
\hline ssI 61110003 & 1 & I & 1 & $D$ & $\mathrm{D}$ \\
\hline ss I 61110004 & $\mathrm{~T}$ & C & C & C & C \\
\hline ss 161110005 & $A$ & G & G & G & G \\
\hline ss I $61 \mid$ I I 0006 & $A$ & $A$ & A & G & G \\
\hline ss I 6 I I I 0007 & C & C & C & $\mathrm{T}$ & $\mathrm{T}$ \\
\hline ssI $61 \mid 10008$ & $D$ & $\mathrm{D}$ & $\mathrm{D}$ & 1 & I \\
\hline ss 161110009 & G & G & G & G & A \\
\hline ss 161110010 & G & $\mathrm{T}$ & $\mathrm{T}$ & $\mathrm{T}$ & $\mathrm{T}$ \\
\hline ss 161151656 & G & G & $\mathrm{T}$ & G & G \\
\hline ss 161151657 & C & $\mathrm{T}$ & C & C & C \\
\hline ss 161151658 & $\mathrm{~T}$ & C & $\mathrm{T}$ & $\mathrm{T}$ & $\mathrm{T}$ \\
\hline ss 161151659 & $\mathrm{~T}$ & $\mathrm{C}$ & C & C & C \\
\hline
\end{tabular}

D - deletion, I - insertion

itsa $\times$ Piétrain population. Least square means of pigs homozygous for haplotype 5 cannot be reliably estimated since there are only two animals in that group.

\section{Expression of PPARD variants}

Our association studies suggest evidence for association between PPARD variants and backfat thickness. However, since two different haplotypes were associated with an opposing effect on backfat thickness in two different pig populations, it is unclear if the observed associations are caused by a variation in PPARD or a causal mutation in linkage disequilibrium to PPARD. None of the SNPs located in the coding region cause an amino acid exchange. For this reason, there is no obvious functional candidate for the observed association. However, numerous studies have identified cis-regulatory and synonymous mutations with functionally significant consequences for morphology, physiology and behaviour [14-16]. To estimate whether the detected polymorphisms in PPARD could be functional, gene expression of the PPARD haplotypes 4 and 5 was studied. Pigs containing the desired PPARD variants were bred by artificial insemination of F3 sows with Piétrain boars known to possess haplotype 4 and haplotype 5, respectively. This was necessary since none of the F3 animals possessed haplotypes 4 and 5. Consequently, offspring carrying no or one haplotype 4 or 5 allele was obtained. Tissue samples from liver were collected within $30 \mathrm{~min}$ after exsanguation and stored in RNAlater ${ }^{\mathrm{TM}}$ (Qiagen, Hilden, Germany). RNA was isolated, reverse transcribed and PPAR- $\delta$ expression was analysed in a relative quantification approach with Tata-Box binding protein (TBP) and Topoisomerase 2 beta (TOP2B) as reference genes. PPAR- $\delta$ expression is significantly reduced by haplotype 5 and increased by haplotype 4 (Table 4). Interestingly, haplotypes 4 and 5 are the two haplotypes associated with backfat thickness. The presence of haplotype 5 increased backfat thickness in a Mangalitsa $\times$ Piétrain cross and the presence of haplotype 4 decreased backfat thickness in a German Landrace population. In accordance with these findings, PPAR- $\delta$ expression is altered in opposite directions by these two haplotypes.

Statistical significant reduced expression was reached by haplotype 1 as well. However, in the analysis absence of haplotype 1 was compared with mostly heterozygous presence of haplotype 1. Further analysis of PPAR- $\delta$ expression in animals with diplotypes containing haplotype 1 showed a reduced expression only in animals carrying diplotype $1 / 5$, which is most likely caused by haplotype 5.

Table 3: Association analysis of PPARD haplotypes and backfat thickness in the middle of the back

\begin{tabular}{|c|c|c|c|c|c|c|c|c|}
\hline \multirow[t]{2}{*}{ Breed } & \multirow[t]{2}{*}{ Haplotype } & \multicolumn{3}{|c|}{ Number of animals } & \multicolumn{3}{|c|}{ Haplotype LS mean [mm] (SE) } & \multirow[t]{2}{*}{ P-value } \\
\hline & & $-1-$ & $+/-$ & $+/+$ & $-/-$ & $+/-$ & $+/+$ & \\
\hline \multirow[t]{4}{*}{ F2 Mangalitsa $\times$ Piétrain } & 1 & 97 & 280 & 222 & $29.50(0.56)$ & $29.29(0.32)$ & $29.16(0.37)$ & 0.902 \\
\hline & 2 & 300 & 247 & 52 & $29.30(0.33)$ & $29.14(0.35)$ & $29.80(0.81)$ & 0.744 \\
\hline & 3 & 522 & 77 & - & $29.38(0.24)$ & $28.57(0.72)$ & - & 0.311 \\
\hline & 5 & 553 & 46 & - & $29.09(0.23)$ & $31.52(1.00)$ & - & 0.022 \\
\hline \multirow[t]{5}{*}{ German Landrace } & 1 & 544 & 124 & 7 & $20.56(0.16)$ & $20.96(0.33)$ & $18.76(1.39)$ & 0.220 \\
\hline & 2 & 193 & 366 & 116 & $20.37(0.27)$ & $20.63(0.19)$ & $20.96(0.34)$ & 0.388 \\
\hline & 3 & 579 & 95 & $\mathrm{I}$ & $20.57(0.15)$ & $20.92(0.38)$ & 16.01 & 0.320 \\
\hline & 4 & 271 & 314 & 90 & $20.86(0.22)$ & $20.64(0.21)$ & $19.78(0.38)$ & 0.034 \\
\hline & 5 & 654 & 19 & 2 & $20.58(0.14)$ & $21.92(0.85)$ & $19.00(2.60)$ & 0.242 \\
\hline
\end{tabular}




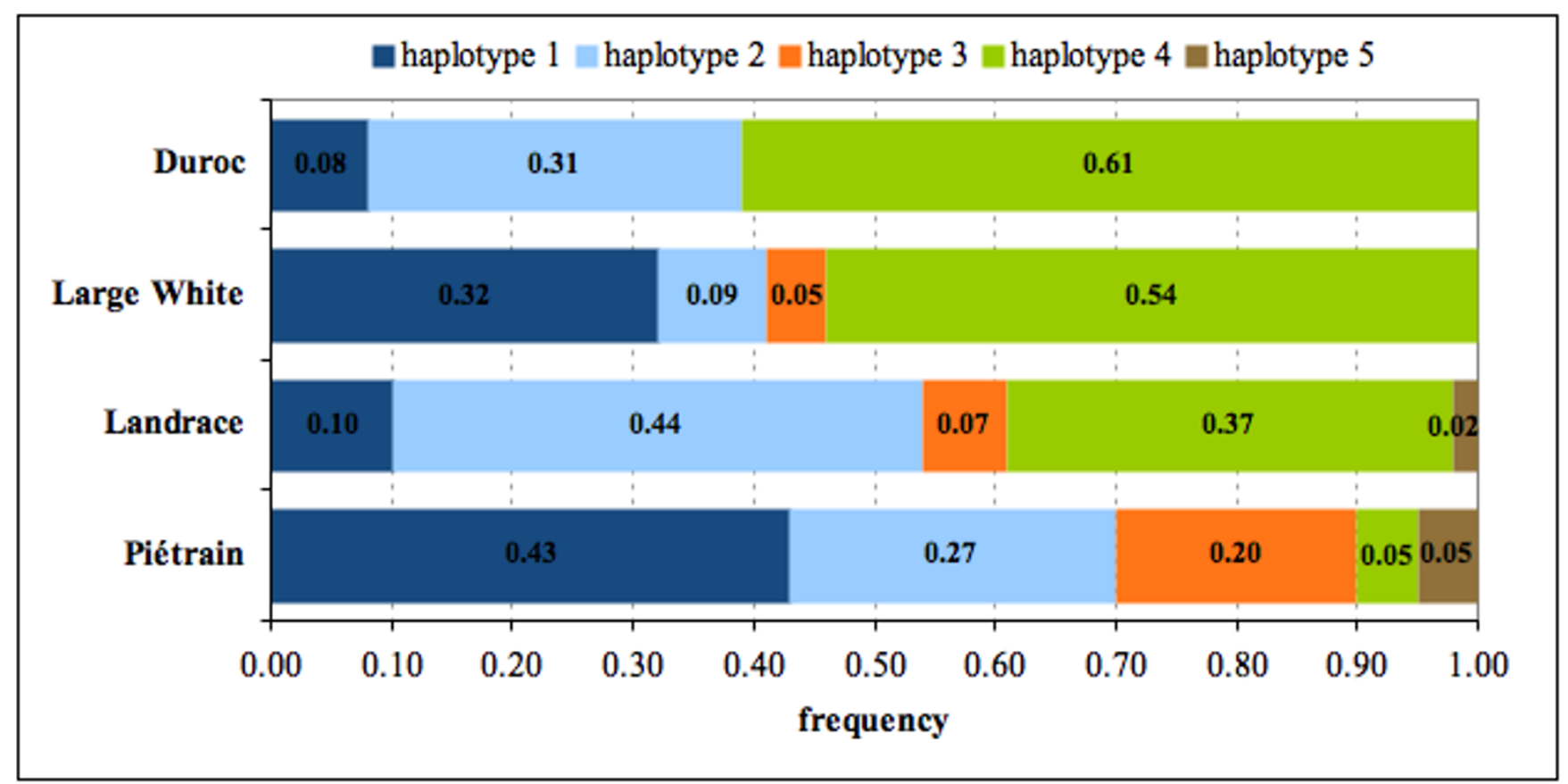

Figure 2

Frequency of PPARD haplotypes indifferent pig breeds.

\section{Discussion}

PPARD was chosen as a candidate for backfat thickness because of the central role of PPAR- $\delta$ in the regulation of lipid metabolism and because of its localisation in a major QTL region for backfat thickness on chromosome 7. The candidate gene analysis of porcine PPARD presented here identified only silent mutations. Nonetheless, it reveals an association of PPARD haplotypes 4 and 5 with backfat thickness. Haplotype 5 is associated with increased backfat thickness in F2 Mangalitsa $\times$ Piétrain pigs, and haplotype 4 with decreased backfat thickness in the German Landrace population. It was not possible to carry out an association study with haplotypes 4 and 5 in the same pig population, as haplotype 4 is absent in the F2 Mangalitsa $\times$ Piétrain generation and haplotype 5 is

Table 4: mRNA expression of PPAR- $\delta$ porcine liver

\begin{tabular}{|c|c|c|c|c|}
\hline \multirow[t]{2}{*}{ Haplotype } & \multicolumn{2}{|c|}{ number of animals } & \multicolumn{2}{|c|}{ PPAR- $\delta$ expression } \\
\hline & $-/-$ & $+/-$ & $\mathbf{R}$ & p-value \\
\hline I & 11 & 42 & 0.47 & 0.044 \\
\hline 2 & 43 & 10 & 1.69 & 0.182 \\
\hline 3 & 35 & 18 & 1.14 & 0.704 \\
\hline 4 & 32 & 21 & 2.13 & 0.014 \\
\hline 5 & 41 & 12 & 0.35 & 0.004 \\
\hline
\end{tabular}

Ratios indicate the influences of a PPARD haplotype on mRNA levels. Ratio $R=I$ indicates no influence, $R>I$ indicates mRNA levels are increase by the haplotype and $R<I$ indicates a decrease. P-values were estimated by a permuation method. extremely rare in German Landrace. Analogous to numerous QTL studies [2,5-7], the same paradox of lower backfat caused by the allele originating from the breed with more backfat was revealed. In the Mangalitsa $\times$ Piétrain cross, haplotype 5 originates from the lean Piétrain breed and causes higher backfat.

Interestingly, the opposite effect of PPARD haplotypes 4 and 5 on backfat thickness is reflected by an opposite effect of these two haplotypes on PPAR- $\delta$ mRNA levels. Haplotype 4 is associated with reduced backfat thickness, and it significantly increases mRNA expression of PPAR- $\delta$ in liver. Haplotype 5 is associated with higher backfat thickness, and it significantly decreases PPAR- $\delta$ expression in liver. These findings are in line with studies demonstrating a decrease of body fat in mice caused by PPAR- $\delta$ overexpression [17]. In conclusion, findings from the association study, when considered together with results from the PPAR- $\delta$ expression study may suggest an effect of PPARD variants on backfat thickness. However, this study was not able to verify that, because no obvious functional candidate was identified. None of the SNPs located in the coding sequence result in an amino acid exchange. None of the SNPs in the analysed 2000 bp region of the PPARD promoter are located in a conserved region or a region that is known to harbour a transcription factor binding site [18]. Differences in mRNA levels between PPARD haplotypes suggest that functionality is caused either by influences on mRNA stability or by differences in PPAR- $\delta$ 
mRNA de-novo synthesis. None of the SNPs located in mRNA exhibit a large influence on the mRNA secondary structure (data not shown). However, control elements located in introns or far away from the gene can enhance or inhibit mRNA expression. This makes it difficult to identify the functional variant, especially as the observed effect might be due to not only one, but several genetic variants interacting with each other. In conclusion, this study was not able to detect a genetic variant in PPARD that is likely to cause the observed association. Hence, the effect on backfat thickness can originate from another variant in linkage disequilibrium to the analysed haplotypes located either in PPARD or a neighbouring gene.

\section{Conclusion}

The candidate gene study involving PPARD revealed association between PPARD variants and backfat thickness. However, it is not clear whether or not the association is caused by PPARD or a neighbouring gene in linkage disequilibrium, especially since no obvious functional variant was identified. Further studies are required to determine whether the observed associations are present in other pig populations. Additionally, other candidate genes at the location of the QTL on porcine chromosome 7 should be considered.

\section{Methods \\ Animals \\ Mangalitsa $\times$ Piétrain intercross}

Initially, two Swallow Bellied Mangalitsa boars were crossed to 13 Piétrain sows to produce an F1 generation. All Piétrain sows were homozygous for the mutant Cys614 allele at the RYR1 locus. Selected F1 sows $(\mathrm{n}=18)$ and boars $(n=5)$ were mated and the resulting F2 generation was used for the analysis presented here. Animals were fed ad libitum. Male pigs were castrated. Pigs were slaughtered when they reached a weight of about $95 \mathrm{~kg}$. Backfat thickness at the middle of the back was measured after slaughtering according to German Pig Breeders Standards [19]. A mean backfat thickness of $29.27 \mathrm{~mm}$ with a standard deviation of $5.57 \mathrm{~mm}$ was observed.

Association analyses were carried out in the F2 generation. F3 sows were backcrossed with Piétrain boars to introduce a desired PPARD gene variant (haplotypes 4 and 5) that was lost in F3. The genotypes of Piétrain boars were determined in order to assure the presence of the PPARD haplotypes 4 and 5 in the employed Piétrain boars. Seven F4 litters were used for gene expression studies. These seven litters correspond to a total number of 56 animals, 31 of them male and 25 female. They were slaughtered at $80 \pm$ 2 days of age with an average weight of $25.6 \mathrm{~kg}$. Tissue samples (approximately $0.5 \mathrm{~g}$ ) for RNA isolation were collected from liver, longissimus muscle, backfat, heart, spleen, brain, kidney, ham and lung within 30 min after exsanguination and stored in $5 \mathrm{ml}$ of RNAlater ${ }^{\mathrm{TM}}$ (Qiagen, Hilden, Germany).

\section{Commercial Pig Breeds}

A total of 722 German Landrace pigs raised under standardized condition for performance testing between 2002 and 2005 in Bavaria were used for association analysis. Backfat measurement was carried out after slaughtering according to German Pig Breeders Standards [19]. A mean backfat thickness of $20.64 \mathrm{~mm}$ with a standard deviation of $3.78 \mathrm{~mm}$ was observed.

The estimation of allele frequencies in different breeds was performed in 213 Piétrain, 40 German Landrace, 13 Large White, 24 Meishan and 45 Duroc animals.

\section{BAC clone}

A bacterial artificial chromosome (BAC) clone containing PPARD was identified in-silico with the help of the genomic location of the human gene from the Porcine BAC End Sequencing Project [20]. Colony PCRs with primers located in the putative promoter region and in exon 8 (primer pair 2 and 15) were carried out to ensure that the clone contains PPARD. Sequencing of BAC PigE255B24 was performed by a shotgun approach as follows: Sheared fragments of $3 \mathrm{~kb}$ in length (GeneMachines) were subcloned separately into pUC19 vector. $4 \times 384$ clones were selected from the clone library. Plasmid DNA was prepared following a protocol supplied by Millipore (Schwalbach, Germany). Cycle sequencing was routinely performed using ABI PRISM BigDye Terminator v 3.1. Ready Reaction Cycle Sequencing Kit (Applied Biosystems, Foster City, CA, USA) and M13f/M13r primer. All separations were run on ABI 3730XL capillary sequencers. Data were assembled and edited using the GAP4 program [21].

\section{DNA-Isolation, primer design, PCR, Re-sequencing}

DNA was isolated from blood, semen and ear tissue by standard methods. Primers were designed with Primer 3 Software [22] based on porcine GSS available through the NCBI homepage [23] and on derived BAC sequences. The primers used for Polymerase Chain Reaction (PCR) are summarized in Table 5. A standard PCR reaction contained $0.5 \mu \mathrm{M}$ of each Primer, $200 \mu \mathrm{M}$ of each dNTP (Fermentas, St. Leon-Rot, Germany), 0.5 U Taq-Polymerase (Qiagen), 50 ng genomic DNA and the diluted 10-fold PCR buffer supplied by Qiagen (Tris/HCl buffer $(\mathrm{pH}=$ 8.7) containing $\left.15 \mathrm{mM} \mathrm{MgCl}_{2}, \mathrm{KCl},\left(\mathrm{NH}_{4}\right)_{2} \mathrm{SO}_{4}\right)$ in a total volume of $20 \mu \mathrm{L}$. After preincubation at $94^{\circ} \mathrm{C}$ for $3 \mathrm{~min}$, the PCR mixture underwent 30 cycles of denaturation at $94^{\circ} \mathrm{C}$ for $30 \mathrm{~s}$, annealing for $60 \mathrm{~s}$ and extension at $72^{\circ} \mathrm{C}$ for $60 \mathrm{~s}$. A final elongation step at $72^{\circ} \mathrm{C}$ for $3 \mathrm{~min}$ followed. The annealing temperature was adjusted to the requirements of the primers (Table 5). Cleaning of PCR 
Table 5: Primer sequences and PCR conditions

\begin{tabular}{|c|c|c|c|}
\hline & localization & primer & annealing $\operatorname{Tm}\left[{ }^{\circ} \mathrm{C}\right]$ \\
\hline 1 & promoter & $\begin{array}{l}\text { GAATGCCTCTTCCTGAATGG } \\
\text { CCTCCTTGCCTTTGATATTGA }\end{array}$ & 60 \\
\hline 2 & promoter & $\begin{array}{l}\text { GGCAAGGAGGTTAACATCTGA } \\
\text { GAGACTCCCCTGAATCACCA }\end{array}$ & 60 \\
\hline 3 & promoter & $\begin{array}{l}\text { GCAGCACAGTTTCCTCCAG } \\
\text { GCTGCTTGCCTATCCACTTC }\end{array}$ & 60 \\
\hline 4 & promoter, exon I, intron I & $\begin{array}{l}\text { GGATTAATGGGAAAAGTTTTGG } \\
\text { AGCAACTAACGACCGTGGAC }\end{array}$ & 59 \\
\hline 5 & intron 1 , exon 2 & $\begin{array}{l}\text { TCCAGGATTGAGAAAAATCTGC } \\
\text { CAAGAATCCTAAACCTGGGATG }\end{array}$ & 60 \\
\hline 6 & exon 3 , intron 3 & $\begin{array}{l}\text { TCACCCTCTCATCCTCTACACC } \\
\text { GCTGATTAGCGATAGAGTGACC }\end{array}$ & 60 \\
\hline 7 & exon 4 , intron 4 & $\begin{array}{c}\text { CTGCCCCTGCTGTGTCTG } \\
\text { AGGAAGAACCTACAAGCACCAC }\end{array}$ & 65 \\
\hline 8 & intron 4 & $\begin{array}{l}\text { GCTTCCACTACGGAGTCCAC } \\
\text { GATGAGGGAGGGTGAGAAAAG }\end{array}$ & 59 \\
\hline 9 & exon 5 & $\begin{array}{l}\text { AACCATCTTTCTCCСTTCTTCG } \\
\text { GCACTCCCTTCTGTCTCTGG }\end{array}$ & 60 \\
\hline 10 & intron 5 & $\begin{array}{l}\text { GCTGGGCATGTCTCACAAC } \\
\text { CAAAGCGAATGGCTGCATAG }\end{array}$ & 59 \\
\hline 11 & exon 6 , intron 6 , exon 7 & $\begin{array}{l}\text { CTACAGCGCCTACCTGAAAAAC } \\
\text { GAGAGCCAGGTCACTATCATCG }\end{array}$ & 60 \\
\hline 12 & intron 5 , exon 6 , intron 6 , exon 7 & $\begin{array}{l}\text { GCATCTCTGGGGAGTTCCTA } \\
\text { TCGTTGAGGAAGAGGTGGTC }\end{array}$ & 60 \\
\hline 13 & exon7, intron 7 & $\begin{array}{l}\text { TCTCTGTCTTTGCTCGTGTACC } \\
\text { CCAGGAGGGCTGAGTGTG }\end{array}$ & 67 \\
\hline 14 & intron 7 & $\begin{array}{c}\text { TAGTGACCTGGCTCTCTTCATC } \\
\text { ATGGCCTCCACCTGTGAC }\end{array}$ & 59 \\
\hline 15 & exon 8 & $\begin{array}{c}\text { CCAAGGTCCCCTGTCCTC } \\
\text { GAGAGGAGGCAGGGCTATAAG }\end{array}$ & 60 \\
\hline
\end{tabular}

products was undertaken in a MultiScreen ${ }^{\circledR}$ PCR $\mu 96$ Plate (Millipore). The amount of cleaned PCR product used for sequencing reaction varied from 2 to $5.5 \mu \mathrm{L}$ depending on fragment size and PCR efficiency. In addition to the PCR products, the sequencing reaction consisted of $2 \mu \mathrm{L}$ reaction mix of the BigDye ${ }^{\circledR}$ Terminator v1.1 Cycle Sequencing Kit (Applied Biosystems) and $0.5 \mu \mathrm{M}$ primer. The volume of the sequencing reaction mix was adjusted to $10 \mu \mathrm{L}$. Thermal cycling for each primer was at $96^{\circ} \mathrm{C}$ for $10 \mathrm{~s}$, $51^{\circ} \mathrm{C}$ for $5 \mathrm{~s}$ and $60^{\circ} \mathrm{C}$ for $4 \mathrm{~min}$, for a total of 35 cycles. The sequencing reaction was cleaned via gel filtration with
Sephadex G-50 (Sigma-Aldrich, Steinheim, Germany) in a MultiScreen ${ }^{\circledast} 96$ well filtration plate (Millipore). DNA sequencing was performed on an ABI 377 automated sequencer (Applied Biosystems) according to manufactures instructions. Obtained sequences were analyzed using Phred/Phrap/Polyphred/Consed software suite [2427].

\section{Genotyping}

Genotyping of tag SNPs was performed by PCR followed by restriction enzyme assays. For RFLP analysis, 3 - $7 \mu \mathrm{l}$ of 
the appropriate PCR product were mixed with the enzyme and the supplied buffer. The volume was adjusted to $10 \mu \mathrm{l}$ using water. An overview of enzymes used and reaction conditions employed is given in Table 6 . After incubation at $37^{\circ} \mathrm{C}$ the resulting fragments were separated on a $2 \%$ agarose gel.

\section{Bioinformatics}

Transcription factor binding sites were predicted by Cister [28], P-Match [29] and MatInspector [30]. Prediction of mRNA secondary structure was carried out using the Mfold web server [31].

\section{Statistical analyses}

Haplotypes were inferred using PHASE software version 2.1.1 [32,33] with default parameters (number of iterations $=100$, thinning interval $=1$, burn-in $=100$ ).

Statistical analyses were carried out using the R environment for statistical computing version 2.4.1 [34]. Association between haplotypes and backfat thickness was estimated within 599 F2 Mangalitsa $\times$ Piétrain animals by a linear model with fixed effects of haplotype, dam and gender as well as covariate of living weight. For normalisation, backfat values were transformed to the power of 0.75. The model for estimating the effect of PPARD variants in the German Landrace population contained the performance testing station and weight as the only covariates because unrelated castrated animals were chosen. Pvalues were corrected for multiple testing of four haplotypes by Bonferroni correction. Least square (LS) means and their standard errors were calculated with untransformed backfat data based on the model described above using the effects package for R [35].

\section{Gene expression studies}

Total RNA from 20 mg of RNAlater ${ }^{\mathrm{TM}}$ (Qiagen) stabilised liver tissue was isolated using the RNeasy ${ }^{\circledR}$ Plus Mini Kit (Qiagen). Homogenisation of the tissue was achieved by processing the sample in the FastPrep ${ }^{\circledast}$ Instrument (Qbiogene, Inc, CA, USA) for 40 seconds at a speed setting of 6.5 $\mathrm{m} / \mathrm{s}$ using Lysing Matrix D (Qbiogene). Synthesis of cDNA was carried out for all samples at the same time with $1 \mu \mathrm{g}$ RNA and 500 ng random pentadecamer primers using the First Strand cDNA Synthesis Kit (Fermentas). Quantitative Real-Time PCR was carried out on an ABI PRISM ${ }^{\circledR} 7000$ Sequence Detection System (Applied Biosystems). RealTime PCR reaction consisted of Power SYBR ${ }^{\circledR}$ Green PCR Master Mix (Applied Biosystems), primers in an optimised concentration (PPARD: $100 \mathrm{nM}$ 5'-CATGTCTCACAACGCCATTCG-3'/300 nM 5'-ATGTCGTGGATCAC AAAGGGC-3'; TBP: 200 nM 5'-GATGGACGTTCGGTTTAGG-3'/300 nM 5'-AGCAGCACAGTACGAGCAA-3'; TOP2B: 200 nM 5'-GCTGGTGGCAAACACTCACTGG-3'/
500 nM 5'-TGGAAAAACTCCGTATCTGTCTC-3') and diluted cDNA in a reaction volume of $20 \mu \mathrm{l}$.

After activation of Hot Start Polymerase by $10 \mathrm{~min}$ incubation at $95^{\circ} \mathrm{C}$ a 2 -step PCR program was used consisting of 45 cycles of $15 \mathrm{~s}$ at $95^{\circ} \mathrm{C}$ and $1 \mathrm{~min}$ at $60^{\circ} \mathrm{C}$. In case of PPARD annealing temperature had to be increased to $66^{\circ} \mathrm{C}$ to avoid primer dimers.

Crossing point (CP) and efficiency were calculated for each individual PCR reaction using ABI PRISM ${ }^{\circledast} 7000$ SDS Software (Applied Biosystems) and the MoBPA package in $\mathrm{R}$ [36], respectively. For statistical analysis a modified version of the REST $^{\circ}$ (Relative Expression Software Tool) method was applied [37]. The algorithm of REST $^{\circ}$ allows group-wise comparison of relative expression data in Real-Time PCR. However, this method assumes equal amplification efficiencies in all samples. The method used here was adapted to account for differences in PCR efficiency.

Mean expression differences between different PPARD genotypes for all genes of interest were calculated as follows. In a first step, the expression $\mathrm{E}$ for each animal and each gene was determined (Equation 1).

$$
E=\text { Efficiency }^{C P}
$$

The geometric mean $\bar{E}_{g}$ of these expression values was calculated within a group of $N_{g t}$ animals with the same genotype gt (Equation 2).

$$
\bar{E}_{g}=\left(\prod_{i=1}^{N_{g t}} E_{i}\right)^{1 / N_{g t}}
$$

Finally, the mean expression of one genotype (gt2) was divided by the mean expression of the other genotype (gt1). For SNPs where 3 genotypes were present in the analysed animals the expression of one genotype (gt1) was compared to a pool of animals with the two other genotypes (gt2). The mean expression difference $R$ was calculated by dividing the ratio for the gene of interest by the geometric mean of the ratios for $M$ reference genes (Equation 3).

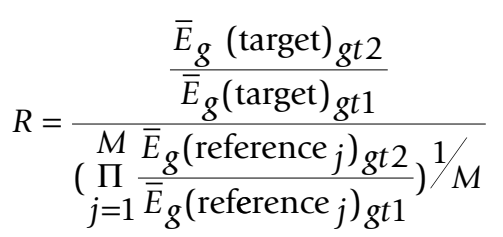

A mean expression difference $R=1$ characterises no effect of the genotype on expression of the analysed gene. The 
Table 6: Restriction enzymes

\begin{tabular}{llllll}
\hline SNP & Enzyme & $\begin{array}{l}\text { Specificity* } \\
\mathbf{5}^{\prime} \rightarrow \mathbf{3}^{\prime}\end{array}$ & $\begin{array}{l}\text { Primer } \\
\text { pair }\end{array}$ & $\begin{array}{l}\text { Units per } \\
\text { reaction }\end{array}$ & $\begin{array}{l}\text { Incubation } \\
\text { time }\end{array}$ \\
\hline ss161109995 & Bsp/43II & PuGCGCPy & 3 & 0.5 & $14 \mathrm{~h}$ \\
ss161109997 & Bsh/2361 & CGCG & 5 & 0.5 & $14 \mathrm{~h}$ \\
ss161109998 & Eco721 & CACGTG & 5 & 5 & $3 \mathrm{~h}$ \\
ss161110009 & Esp31 & CGTCTC & 12 & 0.5 & $14 \mathrm{~h}$ \\
ss161110010 & EcoO1091 & PuGGNCCPy & 15 & 0.5 & $14 \mathrm{~h}$
\end{tabular}

*polymorphic nucleotide marked in bold

significance of a derivation from $R=1$ was estimated by a permutation technique (number of permutations = 5000). The natural logarithm of $R$ was used to obtain valid $\mathrm{p}$-values for a two-sided significance test, because the untransformed values of $R$ are left-skewed.

\section{List of abbreviations}

BAC: Bacterial artificial chromosome; GSS: Genome survey sequence; LS: Least square; MAF: Minor allele frequency; PCR: Polymerase chain reaction; RFLP: Restriction Fragment Length Polymorphism; SNP: Single nucleotide polymorphism; QTL: Quantitative trait locus.

\section{Authors' contributions}

KM carried out genetic studies, participated in statistical analysis and drafted the manuscript. HS participated in statistical analysis and edited the manuscript. RF designed the study and edited the manuscript. HB coordinated the BAC sequencing carried out by SS and MS. All authors read and approved the final manuscript.

\section{Acknowledgements}

We thank Bettina Hayn, Hermine Kienberger, Dagmar Reinl and Theresia Böhm for excellent technical assistance and Mahdi Osman for his contribution to data analysis. The expert animal care by the staff of WZW Experimental Station Thalhausen is greatly appreciated. We are grateful for specimen and DNA samples we received from Besamungsstation Bergheim e.V. and Bayrische Landesanstalt für Landwirtschaft, Grub (Germany). This project was supported by the Deutsche Forschungsgemeinschaft, Germany (DFG) grant FR I284/2-I to Ruedi Fries. Sequencing of the BAC clone was carried out within QuaLIPID, a project funded by the German Federal Ministry of Education and Research (grant 03I339ID to Helmut Blöcker).

\section{References}

I. Hu Z-L, Dracheva S, Jang W, Maglott D, Bastiaansen J, Rothschild M, Reecy J: A QTL resource and comparison tool for pigs: PigQTLDB. Mammalian Genome 2005, I 6( I0):792.

2. Rohrer GA, Keele JW: Identification of quantitative trait loci affecting carcass composition in swine: I. Fat deposition traits. J Anim Sci 1998, 76(9):2247-2254.

3. Milan D, Bidanel JP, lannuccelli N, Riquet J, Amigues $Y$, Gruand J, Le Roy P, Renard C, Chevalet C: Detection of quantitative trait loci for carcass composition traits in pigs. Genet Sel Evol 2002, 34(6):705-728.

4. Malek M, Dekkers JC, Lee HK, Baas TJ, Rothschild MF: A molecular genome scan analysis to identify chromosomal regions influencing economic traits in the pig. I. Growth and body composition. Mamm Genome 200I, I 2(8):630-636.
5. de Koning DJ, Janss LLG, Rattink AP, van Oers PAM, de Vries BJ, Groenen MAM, Poel JJ van der, de Groot PN, Brascamp EW, van Arendonk JAM: Detection of Quantitative Trait Loci for Backfat Thickness and Intramuscular Fat Content in Pigs (Sus scrofa). Genetics 1999, I 52(4): 1679-1690.

6. Yue G, Stratil A, Cepica S, Schroffel J, Schroffelova D, Fontanesi L, Cagnazzo M, Moser G, Bartenschlager H, Reiner G, et al:: Linkage and QTL mapping for Sus scrofa chromosome 7. Journal of Animal Breeding and Genetics 2003, I 20(s I):56-65.

7. de Koning DJ, Rattink AP, Harlizius B, Groenen MAM, Brascamp EW, van Arendonk JAM: Detection and characterization of quantitative trait loci for growth and reproduction traits in pigs. Livestock Production Science 200I, 72(3): 185-198.

8. Tanaka M, Suzuki K, Morozumi T, Kobayashi E, Matsumoto T, Domukai M, Eguchi-Ogawa T, Shinkai H, Awata T, Uenishi H: Genomic structure and gene order of swine chromosome 7ql.I-$>$ qI.2. Anim Genet 2006, 37(1):10-16.

9. Barbosa A, Demeure O, Urien Cl, Milan D, Chardon P, Renard C: A physical map of large segments of pig Chromosome 7qIIq14: comparative analysis with human Chromosome 6p2I. Mammalian Genome 2004, I 5( I 2):982-995.

10. Tanaka T, Yamamoto J, Iwasaki S, Asaba H, Hamura H, lkeda Y, Watanabe M, Magoori K, loka RX, Tachibana K, et al: Activation of peroxisome proliferator-activated receptor \{delta\} induces fatty acid \{beta\}-oxidation in skeletal muscle and attenuates metabolic syndrome. PNAS 2003, 100(26): 15924-15929.

II. Kuehn LA, Rohrer GA, Nonneman DJ, Thallman RM, Leymaster KA: Detection of single nucleotide polymorphisms associated with ultrasonic backfat depth in a segregating Meishan $x$ White Composite population. J Anim Sci 2007, 85(5): I I I I- I I 9.

12. Demars J, Riquet J, Sanchez MP, Billon Y, Hocquette JF, Lebret B, lannuccelli N, Bidanel JP, Milan D, Gondret F: Metabolic and histochemical characteristics of fat and muscle tissues in homozygous or heterozygous pigs for the body composition QTL located on chromosome 7. Physiol Genomics 2007, 30(3):232-24I.

13. Ponsuksili S, Murani E, Walz C, Schwerin M, Wimmers K: Pre- and postnatal hepatic gene expression profiles of two pig breeds differing in body composition: insight into pathways of metabolic regulation. Physiol Genomics 2007, 29(3):267-279.

14. Chamary JV, Parmley JL, Hurst LD: Hearing silence: non-neutral evolution at synonymous sites in mammals. Nat Rev Genet 2006, 7(2):98.

15. Kimchi-Sarfaty C, Oh JM, Kim I-W, Sauna ZE, Calcagno AM, Ambudkar SV, Gottesman MM: A "Silent" Polymorphism in the MDR I Gene Changes Substrate Specificity. Science 2007, 315(58II):525-528.

16. Wray GA: The evolutionary significance of cis-regulatory mutations. Nat Rev Genet 2007, 8(3):206.

17. Luquet S, Lopez-Soriano J, Holst D, Fredenrich A, Melki J, Rassoulzadegan M, Grimaldi PA: Peroxisome proliferator-activated receptor \{delta\} controls muscle development and oxidative capability. FASEB J 2003, I7(I5):2299-230I.

18. Skogsberg J, Kannisto K, Roshani L, Gagne E, Hamsten A, Larsson C, Ehrenborg E: Characterization of the human peroxisome proliferator activated receptor delta gene and its expression. Int J Mol Med 2000, 6(I):73-8I.

19. Richtlinie für die Stationsprüfung auf Mastleistung, Schlachtkörperwert und Fleischbeschaffenheit beim Schwein [http://www.zds-bonn.de/download.php/790/rinkp04.pdf] 
20. Porcine BAC End Sequencing Project [http:// www.sanger.ac.uk/Projects/S scrofa/BES.shtml]

21. Staden R: The Staden sequence analysis package. Mol Biotechnol 1996, 5(3):233-241.

22. Primer3 [http://frodo.wi.mit.edu/primer3/]

23. National Center for Biotechnology Information [http:// www.ncbi.nlm.nih.gov/]

24. Nickerson DA, Tobe VO, Taylor SL: PolyPhred: automating the detection and genotyping of single nucleotide substitutions using fluorescence-based resequencing. Nucleic Acids Res 1997, 25(I4):2745-275I.

25. Ewing B, Hillier L, WendI MC, Green P: Base-calling of automated sequencer traces using phred. I. Accuracy assessment. Genome Res 1998, 8(3): 175-185.

26. Ewing B, Green P: Base-calling of automated sequencer traces using phred. II. Error probabilities. Genome Res 1998, 8(3): $186-194$

27. Gordon D, Abajian C, Green P: Consed: a graphical tool for sequence finishing. Genome Res 1998, 8(3): 195-202.

28. Frith MC, Hansen U, Weng Z: Detection of cis-element clusters in higher eukaryotic DNA. Bioinformatics 200I, I7( I 0):878-889.

29. Gene Regulation [http://www.gene-regulation.com]

30. Cartharius K, Frech K, Grote K, Klocke B, Haltmeier M, Klingenhoff A, Frisch M, Bayerlein M, Werner T: MatInspector and beyond: promoter analysis based on transcription factor binding sites. Bioinformatics 2005, 2 I ( I 3):2933-2942.

31. Zuker M: Mfold web server for nucleic acid folding and hybridization prediction. Nucl Acids Res 2003, 3 I (I3):3406-34I5.

32. Stephens M, Donnelly P: A comparison of bayesian methods for haplotype reconstruction from population genotype data. Am J Hum Genet 2003, 73(5): I I62-1 I69.

33. Stephens M, Smith NJ, Donnelly P: A new statistical method for haplotype reconstruction from population data. Am J Hum Genet 200I, 68(4):978-989.

34. R: A language and environment for statistical computing [http://www.r-project.org]

35. effects: Effect Displays for Linear and Generalized Linear Models [http://www.r-project.org]

36. Alvarez MJ, Vila-Ortiz G], Salibe MC, Podhajcer OL, Pitossi FJ: Model based analysis of real-time PCR data from DNA binding dye protocols. BMC Bioinformatics 2007, 8:85.

37. Pfaffl MW: A new mathematical model for relative quantification in real-time RT-PCR. Nucl Acids Res 200I, 29(9):e45.

Publish with Biomed Central and every scientist can read your work free of charge

"BioMed Central will be the most significant development for disseminating the results of biomedical research in our lifetime. "

Sir Paul Nurse, Cancer Research UK

Your research papers will be:

- available free of charge to the entire biomedical community

- peer reviewed and published immediately upon acceptance

- cited in PubMed and archived on PubMed Central

- yours - you keep the copyright
BioMedcentral 